\title{
Clinical Implication of Tumor-invasive Status into the Muscularis Propria in T2 Gastric Cancer
}

\author{
KENJI NAKAMURA ${ }^{1}$, MIKA OGIMI ${ }^{1}$, MIFUJI TOMIOKU ${ }^{1}$, HITOSHI HARA ${ }^{1}$, \\ KAZUHITO NABESHIMA ${ }^{1}$ and EIJI NOMURA ${ }^{2}$ \\ ${ }^{1}$ Department of Gastroenterological Surgery, Tokai University School of Medicine, Kanagawa, Japan; \\ ${ }^{2}$ Department of Gastroenterological and General Surgery, Tokai University Hachioji Hospital, Tokyo, Japan
}

\begin{abstract}
Background/Aim: Several studies have investigated prognostic factors in patients with $T 2$ gastric cancer, but no consensus has been reached to date. The aim was to investigate the clinicopathological significance of the status of tumor invasion into the muscularis propria (MP) in T2 gastric cancer patients. Patients and Methods: A total of 113 patients with T2 cancer were enrolled. The status of caner invasion was analyzed according to width (extent of horizontal invasion) and depth (extent of vertical invasion). Results: The prognosis of the group with wide width of invasion $(\geq 1.5 \mathrm{~cm})$ was significantly poorer than that of the group with narrow width of invasion $(<1.5 \mathrm{~cm})$ $(p=0.001)$. Multivariate analysis identified the width, and not the depth, as an independent prognostic factor. The analysis according to AJCC N stage showed that the width, and not the nodal status, was an independent prognostic factor in the N2$N 3$ patients $(p=0.005)$. Conclusion: Measurement of the width of tumor invasion into the MP was useful to understand the malignant potential of $T 2$ gastric cancer.
\end{abstract}

Advanced gastric cancer confined to the muscularis propria (T2 gastric cancer) is as an intermediate-stage carcinoma, between early and advanced cancer $(1,2)$. Therefore, it is considered to have a better prognosis than more advanced cancer, and recently minimally-invasive surgical procedures, such as laparoscopic gastrectomy, have been actively adopted $(3,4)$. However, although at a low frequency, recurrences do occur, and it is clinically important to investigate prognostic factors for $\mathrm{T} 2$ gastric cancer.

This article is freely accessible online.

Correspondence to: Kenji Nakamura, MD, Department of Gastroenterological Surgery, Tokai University School of Medicine, 143 Shimokasuya, Isehara, Kanagawa 259-1193, Japan. Tel: +81 463931121, Fax: +81 463956491, e-mail: nakaken@is.icc.u-tokai.ac.jp

Key Words: Gastric cancer, muscularis propria, prognosis, tumor invasion.
Several studies have investigated prognostic factors in patients with T2 gastric cancer. While studies have been conducted to determine the influence of age $(5,6)$, tumor diameter $(7,8)$, lymph node metastasis $(9,10)$ and macroscopic type (11) on the prognosis, no consensus has been reached yet. Therefore, in this study, we investigated the clinicopathological significance of the status of tumor invasion at the invasive front, namely, in the muscularis propria (MP), in patients with $\mathrm{T} 2$ gastric cancer.

\section{Patients and methods}

Patients. Between January 2006 and December 2016, 980 consecutive patients with gastric cancer underwent curative gastrectomy at the Department of Gastroenterological Surgery of Tokai University School of Medicine. Of these patients, the data of 113 patients with tumor invasion into the MP were analyzed in this retrospective study. The gross classification and histopathological classification were based on the Japanese Classification of Gastric Carcinoma (JCGC) published by the Japanese Gastric Cancer Association (12). Staging was performed according to the American Joint Committee on Cancer (AJCC) staging manual, eighth edition (13). Patients were mainly followed-up on an outpatient basis at our hospital; however, those who had moved to other institutions were asked relevant questions over telephone. Follow-up was continued until December 2018, with a median duration of follow-up of 2129 days (range $=205-4787$ ). Diagnosis of tumor recurrence was suspected on clinical grounds and confirmed by further investigations. In some patients, the initial recurrence was diagnosed at two or more sites, and in such patients, all of the sites were counted as sites of initial recurrence.

The research was conducted in accordance with the ethical standards of the institutional research committee and the 1964 Declaration of Helsinki and its later amendments. This study was approved by the institutional review board of Tokai University Hospital (registration number 18R-150).

Assessment of the status of tumor invasion into the MP. The resected stomach was opened and placed on a flat board with the mucosal side up, and fixed in $10 \%$ formalin. After fixation, the neoplasm was sectioned along the maximum cross-sectional plane parallel to the lesser curvature, based on the general rules of the JCGC (12). Several additional sections parallel to the maximum cross-sectional plane and one section perpendicular to this plane were prepared to 
identify the area with the deepest invasion. The status of caner invasion into the MP was analyzed according to width (extent of horizontal invasion) and depth (extent of vertical invasion). The method that we have previously used to measure the horizontal width of tumor invasion in gastric cancer patients with tumor invasion of the subserosa was applied to the present study (14). Specifically, the width of invasion was defined as the horizontal length of cancerous invasion measured along the upper rim of the MP layer in these cross-sectional planes. The depth was defined as the distance from the upper rim of the MP to the point of deepest tumor penetration. In the patients that a tumor invaded the MP at two or more sites, the maximum width and depth were defined as the width and depth of tumor invasion.

Statistical analysis. The chi-squared test was used to compare categorical data, and the Mann-Whitney $U$-test to compare continuous variables. The cumulative relapse-free survival rates were calculated by the Kaplan-Meier method, and compared by the log-rank test. Multivariate analyses were performed to identify independent prognostic factors. All significant factors from the univariate analyses were entered in the multivariate analysis. The Cox proportional hazards regression model was used to determine the optimal cutoff threshold for the width and depth of invasion of the MP. A $p$-value $<0.05$ was considered as indicative of statistical significance. All the statistical analyses were performed with SPSS, version 25.0J (IBM Corp., Armonk, NY, USA).

\section{Results}

Threshold width and depth of invasion into the MP. The median width of invasion into the MP (WiMP) was $0.75 \mathrm{~cm}$ (range $=0.02-9.85$ ). Relapse-free survival rates were calculated for every $0.5-\mathrm{cm}$ difference in the width of invasion to determine the appropriate threshold. The width of invasion associated with the largest hazard ratio (HR) as determined using the Cox proportional hazard regression model, was considered as the optimal cutoff point. The most significant difference in the survival rate was found at the threshold width of $1.5 \mathrm{~cm}(\mathrm{HR}=3.552, p=0.002)$ (Table I).

The median depth of invasion into the MP was $1.4 \mathrm{~mm}$ (range $=0.1-10.1$ ). To determine the appropriate threshold, a similar analysis was performed for each $0.5-\mathrm{mm}$ difference in the depth of invasion. The results revealed no significant prognostic impact at any depth of invasion. Accordingly, subsequent analyses were performed by dividing all of T2 gastric cancer patients by the WiMP.

Clinicopathologic characteristics according to the WiMP. Of the 113 patients with T2 gastric cancer, the WiMP was $<1.5 \mathrm{~cm}$ in 85 patients (narrow WiMP group) and $\geq 1.5 \mathrm{~cm}$ in 28 patients (wide WiMP group). The clinicopathological factors were compared between these two groups (Table II). The wide WiMP group had a significantly larger tumor diameter $(p=0.001)$ and significantly higher frequency of lymph node metastasis $(p=0.014)$ than the narrow WiMP group.
Table I. Hazard ratio (HR) according to width of invasion of the muscularis propria calculated by the Cox proportional hazards regression model using relapse-free survival.

\begin{tabular}{lccc}
\hline Threshold $(\mathrm{cm})$ & HR & $95 \%$ CI & $p$-Value \\
\hline 0.5 & 2.416 & $0.898-6.502$ & 0.081 \\
1.0 & 2.286 & $0.995-5.286$ & 0.051 \\
1.5 & 3.552 & $1.594-7.917$ & 0.002 \\
2.0 & 1.806 & $0.672-4.856$ & 0.241 \\
2.5 & 1.267 & $0.376-4.267$ & 0.703 \\
\hline
\end{tabular}

CI, Confidence interval.

Table II. Associations between clinicopathological parameters and width of invasion of the muscularis propria in all patients.

\begin{tabular}{|c|c|c|c|}
\hline Variable & $\begin{array}{c}\text { Narrow } \\
\text { WiMP }(\mathrm{n}=85) \\
\mathrm{n}(\%)\end{array}$ & $\begin{array}{c}\text { Wide } \\
\text { WiMP }(\mathrm{n}=28) \\
\mathrm{n}(\%)\end{array}$ & $p$-Value \\
\hline \multicolumn{4}{|l|}{ Age (years) } \\
\hline$<70$ & $50(58.8)$ & $15(53.6)$ & \multirow[t]{2}{*}{0.626} \\
\hline$\geq 70$ & $35(41.2)$ & $13(46.4)$ & \\
\hline \multicolumn{4}{|l|}{ Gender } \\
\hline Male & $59(69.4)$ & $20(71.4)$ & \multirow[t]{2}{*}{0.840} \\
\hline Female & $26(30.6)$ & $8(28.6)$ & \\
\hline Tumor size* $(\mathrm{cm})$ & $3.2(0.6-11.5)$ & $4.3(2.5-12.2)$ & 0.001 \\
\hline \multicolumn{4}{|l|}{ Gross type } \\
\hline Circumscribed & $66(77.6)$ & $19(67.9)$ & \multirow[t]{2}{*}{0.298} \\
\hline Infiltrative & $19(22.4)$ & $9(32.1)$ & \\
\hline \multicolumn{4}{|l|}{ Resection type } \\
\hline Subtotal gastrectomy & 73 (85.9) & $21(75.0)$ & \multirow[t]{2}{*}{0.182} \\
\hline Total gastrectomy & $12(14.1)$ & $7(25.0)$ & \\
\hline \multicolumn{4}{|l|}{ Histologic type } \\
\hline Differentiated & $46(54.1)$ & $13(46.4)$ & \multirow[t]{2}{*}{0.480} \\
\hline Undifferentiated & $39(45.9)$ & $15(53.6)$ & \\
\hline \multicolumn{4}{|l|}{ Lymphatic invasion } \\
\hline Negative & $19(22.4)$ & $4(14.3)$ & \multirow[t]{2}{*}{0.358} \\
\hline Positive & $66(77.6)$ & $24(85.7)$ & \\
\hline \multicolumn{4}{|l|}{ Venous invasion } \\
\hline Negative & $31(36.5)$ & $10(35.7)$ & \multirow[t]{2}{*}{0.942} \\
\hline Positive & $54(63.5)$ & $18(64.3)$ & \\
\hline \multicolumn{4}{|l|}{ Lymph node metastasis } \\
\hline Negative & $53(62.4)$ & $10(35.7)$ & \multirow[t]{2}{*}{0.014} \\
\hline Positive & $32(37.6)$ & $18(64.3)$ & \\
\hline \multicolumn{4}{|l|}{ Adjuvant chemotherapy } \\
\hline Negative & $48(56.5)$ & $10(35.7)$ & \multirow[t]{2}{*}{0.057} \\
\hline Positive & 37 (43.5) & $18(64.3)$ & \\
\hline
\end{tabular}

WiMP, Width of invasion of the muscularis propria. *Data presented as median (range).

Correlation of the WiMP with the prognosis. The prognostic impact of the WiMP was evaluated by univariate and multivariate analyses (Table III). The 5-year relapse-free survival rate was $86.6 \%$ in the narrow WiMP group and $56.3 \%$ in the wide WiMP group (Figure 1), indicating a significantly 


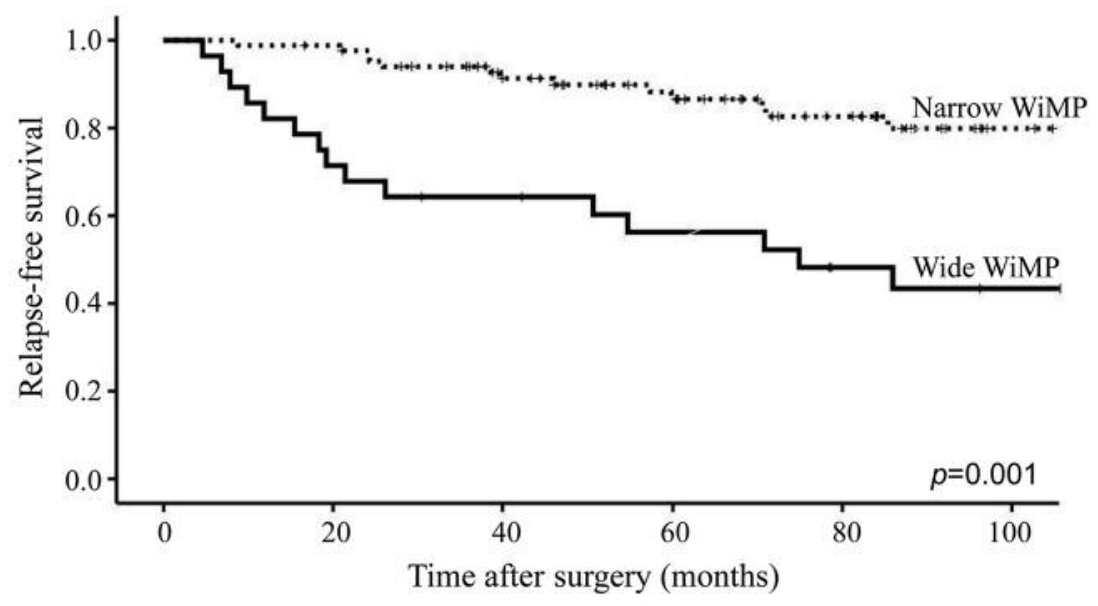

Figure 1. Kaplan-Meier survival curves for relapse-free survival of all patients according to width of invasion of the muscularis propria (WiMP). The group with wide WiMP had a significantly poorer prognosis compared to the group with narrow WiMP. Narrow WiMP, Width of invasion of muscularis propria $<1.5 \mathrm{~cm}$; wide WiMP, width of invasion of muscularis propria $\geq 1.5 \mathrm{~cm}$.

poorer prognosis for the latter $(p=0.001)$. Additionally to the WiMP, the other significant prognostic factors that were identified by the univariate analyses in the 113 patients were the age, tumor size, and lymph node metastasis. In multivariate analysis, age, lymph node metastasis, and WiMP were identified as independent prognostic factors.

Relationship between the WiMP and the prognosis according to the extent of lymph node metastasis. The influence of the WiMP on the prognosis was investigated according to the extent of lymph node metastasis. In the 63 AJCC N0 patients, the narrow $(n=53)$ and wide $(n=10)$ WiMP groups showed 5 -year survival rates of $93.5 \%$ and $90.0 \%$, respectively. In the 23 AJCC N1 patients, the narrow $(n=17)$ and wide $(n=6)$ WiMP groups showed 5-year survival rates of $71.1 \%$ and $66.7 \%$, respectively. Thus, there was no significant difference in prognosis between the narrow and wide WiMP groups in both the N0 patients and N1 patients. The AJCC N2 and N3 patients were combined for the analysis, because there were only $16 \mathrm{~N} 2$ patients and $11 \mathrm{~N} 3$ patients. In the N2-N3 patients, the 5-year survival rates in the narrow $(n=15)$ and wide $(n=12)$ WiMP groups were $80.0 \%$ and $25.0 \%$, respectively, with a significant difference between the two groups $(p=0.015)$ (Figure 2). Besides the WiMP, univariate analysis identified that the adjuvant chemotherapy was a significant prognostic factor for the N2-N3 patients. These two parameters were also identified as independent prognostic factors in multivariate analysis (Table IV).

Relationship between the WiMP and the mode of recurrence. The recurrence rates in the narrow WiMP group was significantly lower than in the wide WiMP group [7.1\% $(6 / 85)$ and $28.6 \%(8 / 28)$, respectively; $p=0.003]$. A review of the mode of recurrence in the narrow WiMP group and wide WiMP group showed development of lymph node metastasis in $3.5 \%(3 / 85)$ and $14.3 \%(4 / 28)$ of the patients, respectively, hematogenous metastasis in $3.5 \%(3 / 85)$ and $10.7 \%(3 / 28)$ of the patients, respectively, and peritoneal metastasis $2.4 \%(2 / 85)$ and $3.6 \%(1 / 28)$ of the patients, respectively. The lymph node recurrence rate was significantly higher in the wide WiMP group $(p=0.041)$.

\section{Discussion}

Studies on the clinical significance of the status of tumor invasion into the MP in patients with T2 gastric cancer have usually focused on the depth of tumor invasion into the MP (15-17). In these studies, the MP was divided for the invasion into a superficial layer composed of the inner circular muscle and a deep layer composed of the outer longitudinal muscle. Some studies have reported that gastric cancer patients showing invasion of the deep layer have a poorer prognosis than those with invasion of only the superficial layer $(16,17)$, whereas others have reported the absence of any significant difference in the prognosis between the two groups (15); thus, no consensus has been reached. Furthermore, few studies have investigated the horizontal width of tumor invasion into the MP in T2 gastric cancer patients (18). In the present study, we measured both the horizontal length and vertical length of tumor invasion into the MP to assess the clinicopathological significance of the status of tumor invasion into the MP.

Patients with wide WiMP had a significantly poorer prognosis than those with narrow WiMP. Multivariate analysis identified the WiMP as an independent prognostic factor. In the present study, we classified the MP into a superficial layer composed of the inner circular muscle and a deep layer 


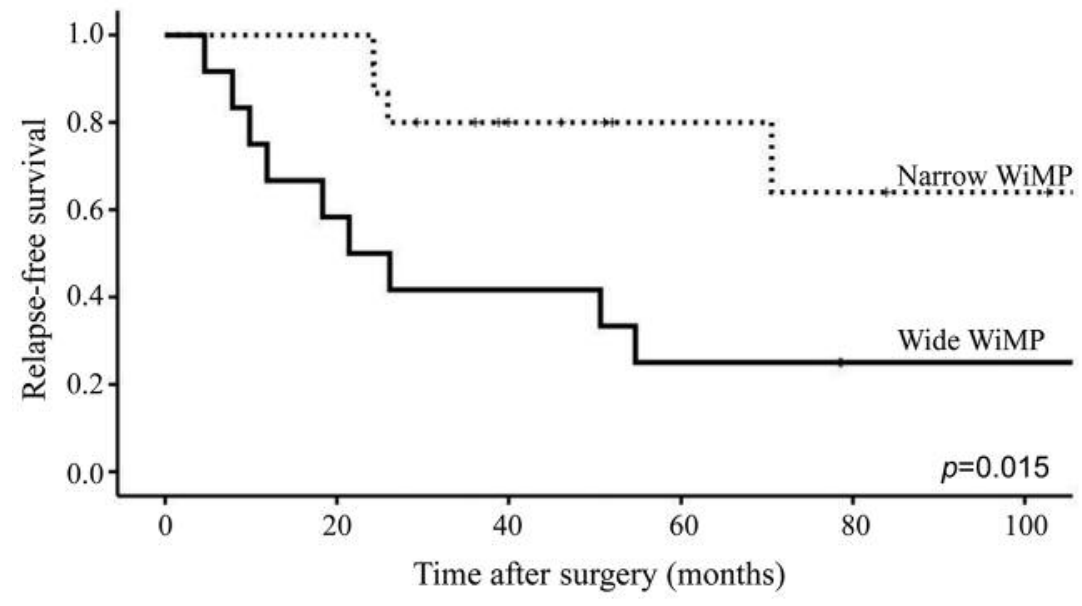

Figure 2. Kaplan-Meier survival curves for relapse-free survival of AJCC N2-N3 patients according to width of invasion of the muscularis propria (WiMP). The group with wide WiMP had a significantly poorer prognosis compared to the group with narrow WiMP. AJCC, American Joint Committee on Cancer; narrow WiMP, width of invasion of muscularis propria $<1.5 \mathrm{~cm}$; wide WiMP, width of invasion of muscularis propria $\geq 1.5 \mathrm{~cm}$.

composed of the outer longitudinal muscle (data not shown). The proportion of patients with tumor invasion up to the deep layer was significantly higher in the wide WiMP group than in the narrow WiMP group $(p=0.001)$. Therefore, the tumor burden in the MP was considered greater in the wide WiMP group than in the narrow WiMP group. Thus, the difference in prognosis between the two groups was considered to be caused by the difference in the tumor burden.

Moreover, in the present study, we measured the width and depth of tumor invasion into the MP, and identified only the width of invasion, and not the depth, as a significant prognostic factor. Several studies have simultaneously measured the width and depth of tumor invasion in submucosal gastric cancer and investigated which of the two is of greater clinicopathological significance (19-22). Sanomura et al. described that the horizontal width of invasion is a more useful predictor of lymph node metastasis than the depth of invasion (19), while similar results were also demonstrated by Fang et al. (21). Kim et al. reported that when the muscularis mucosa was thickened by tumor invasion, the vertical distance was not related to the extent of lymph node metastasis (20). In a study of advanced gastric cancer, Soga et al. measured the vertical distance in patients with tumor invasion of the subserosa and reported that the distance was not a prognostic factor (23). They discussed that the vertical distance is sometimes influenced by the tumor thickness due to interstitial fibrosis. Considering that the depth of tumor invasion was not associated with the prognosis in the present study, it was considered necessary to take into account secondary gastric wall thickening due to tumor penetration when measuring the depth of tumor invasion.

The analysis according to the AJCC N stage showed that there was no difference in the survival rate depending on the
WiMP in N0 or N1 patients. On the other hand, multivariate analysis in the N2-N3 patients revealed that the WiMP was an independent prognostic factor. Liu et al. reported the prognosis according to the extent of lymph node metastasis in T2 gastric cancer patients without distant metastasis (24). They described 5-year survival in N2 and N3 patients of 42\% and $35 \%$, respectively, with a slight difference between the two groups. Sun et al. examined the 5-year survival of T2 gastric cancer patients according to the metastasis ratio and revealed that 5-year survival decreased with worsening of the metastasis ratio from 0 to 0.2 , but remained constant at approximately $30 \%$ when the metastasis ratio became worse than 0.2 (16). In the present study also, examination of N2$\mathrm{N} 3$ patients revealed no significant difference in the 5-year survival rate between $\mathrm{N} 2$ and $\mathrm{N} 3$ patients $(p=0.632)$. The results suggested that the extent of lymph node metastasis may not be a prognostic factor in $\mathrm{T} 2$ gastric cancer patients with advanced lymph node metastasis. Based on the results of our study, we assume that classification according to the WiMP would be useful for patients with advanced lymph node metastasis. However, the number of patients in the present study was small, and further studies on a larger number of patients would be necessary to confirm the results.

In conclusion, the horizontal width of tumor invasion into the MP was found to be an independent prognostic factor in patients with T2 gastric cancer. Patients with wide width of tumor invasion had a significantly poorer prognosis than those with narrow width of tumor invasion. In patients with advanced lymph node metastasis, classification according to the width of invasion, and not classification according to the extent of lymph node metastasis, was correlated with the prognosis. Therefore, in the assessment of patients with T2 gastric cancer, it is important to classify the patients according 
Table III. Univariate and multivariate analyses of prognostic factors for relapse-free survival of all patients.

\begin{tabular}{|c|c|c|c|c|c|}
\hline \multirow[t]{3}{*}{ Variables } & \multirow[t]{3}{*}{ Comparison } & \multicolumn{4}{|c|}{ Relapse-free survival } \\
\hline & & \multicolumn{2}{|c|}{ Univariate analysis } & \multicolumn{2}{|c|}{ Multivariate anaysis } \\
\hline & & HR $(95 \% \mathrm{CI})$ & $p$-Value & $\mathrm{HR}(95 \% \mathrm{CI})$ & $p$-Value \\
\hline Age (years) & $<70 v s . \geq 70$ & $2.651(1.233-5.703)$ & 0.013 & $2.613(1.203-5.676)$ & 0.015 \\
\hline Gender & Male $v s$. female & $0.801(0.340-1.884)$ & 0.611 & & \\
\hline Tumor size $(\mathrm{cm})$ & $<6.0 v s . \geq 6.0$ & $2.649(1.126-6.233)$ & 0.026 & $2.035(0.863-4.802)$ & 0.105 \\
\hline Gross type & Circumscribed $v s$. infiltrative & $1.207(0.531-2.742)$ & 0.653 & & \\
\hline Resection type & SG vs. TG & $1.397(0.530-3.685)$ & 0.499 & & \\
\hline Histologic type & Differentiated $v s$. undifferentiated & $0.526(0.243-1.141)$ & 0.104 & & \\
\hline Lymphatic invasion & Negative $v s$. positive & $4.116(0.975-17.372)$ & 0.054 & & \\
\hline Venous invasion & Negative $v s$. positive & $2.320(0.941-5.725)$ & 0.068 & & \\
\hline Lymph node metastasis & Negative $v s$. positive & $3.545(1.599-7.861)$ & 0.002 & $2.708(1.217-6.030)$ & 0.015 \\
\hline Adjuvant chemotherapy & Negative $v s$. positive & $1.121(0.533-2.361)$ & 0.763 & & \\
\hline $\operatorname{WiMP}(\mathrm{cm})$ & $<1.5 v s . \geq 1.5$ & $4.165(1.979-8.764)$ & 0.001 & $3.614(1.705-7.657)$ & 0.001 \\
\hline
\end{tabular}

CI, Confidence interval; HR, hazard ratio; SG, subtotal gastrectomy; TG, total gastrectomy; WiMP, width of invasion of the muscularis propria.

Table IV. Univariate and multivariate analyses of prognostic factors for relapse-free survival of AJCC N2-N3 patients.

\begin{tabular}{|c|c|c|c|c|c|}
\hline \multirow[t]{3}{*}{ Variables } & \multirow[t]{3}{*}{ Comparison } & \multicolumn{4}{|c|}{ Relapse-free survival } \\
\hline & & \multicolumn{2}{|c|}{ Univariate analysis } & \multicolumn{2}{|c|}{ Multivariate analysis } \\
\hline & & HR $(95 \%$ CI $)$ & $p$-Value & $\mathrm{HR}(95 \% \mathrm{CI})$ & $p$-Value \\
\hline Age (years) & $<70 \mathrm{vs} . \geq 70$ years & $1.176(0.395-3.506)$ & 0.771 & & \\
\hline Gender & Male $v s$. female & $1.050(0.332-3.319)$ & 0.934 & & \\
\hline Tumor size $(\mathrm{cm})$ & $<6.0 v s . \geq 6.0 \mathrm{~cm}$ & $1.250(0.382-4.088)$ & 0.713 & & \\
\hline Gross type & Circumscribed $v s$. infiltrative & $2.050(0.685-6.134)$ & 0.199 & & \\
\hline Resection type & SG $v s$. TG & $0.932(0.253-3.429)$ & 0.916 & & \\
\hline Histologic type & Differentiated $v s$. undifferentiated & $1.032(0.334-3.189)$ & 0.956 & & \\
\hline Lymphatic invasion & Ly1 vs. Ly2-Ly3 & $1.438(0.468-4.419)$ & 0.526 & & \\
\hline Venous invasion & Negative vs. positive & $2.629(0.721-9.585)$ & 0.143 & & \\
\hline Lymph node metastasis & $\mathrm{N} 2$ vs. N3 & $1.032(0.344-3.097)$ & 0.955 & & \\
\hline Adjuvant chemotherapy & Negative $v s$. positive & $0.236(0.068-0.820)$ & 0.023 & $0.065(0.011-0.383)$ & 0.003 \\
\hline WiMP $(\mathrm{cm})$ & $<1.5 v s . \geq 1.5$ & $3.937(1.204-12.867)$ & 0.023 & $10.456(2.008-54.437)$ & 0.005 \\
\hline
\end{tabular}

AJCC, American Joint Committee on Cancer; CI, confidence interval; HR, hazard ratio; SG, subtotal gastrectomy; TG, total gastrectomy; WiMP, width of invasion of the muscularis propria.

to the horizontal width of invasion of the MP invasion, into a narrow invasion group and wide invasion group.

\section{Conflicts of Interest}

The Authors declare that they have no conflicts of interest in regard to this study.

\section{Authors' Contributions}

All Authors contributed to the design and implementation of the study, to the analysis of the results, and to the writing and final approval of the manuscript.

\section{References}

1 Komatsu S, Ichikawa D, Kurioka H, Kan K, Shioaki Y, Ueshima Y, Hamashima T, Lee CJ, Ikeda E, Ueda Y, Otsuji E, Oka T and Yamagishi H: Prognostic and clinical evaluation of patients with T2 gastric cancer. Hepatogastroenterology 52: 965-968, 2005. PMID: 15966242.

2 Marchet A, Mocellin S, Ambrosi A, Morgagni P, Vittimberga G, Roviello F, Marrelli D, de Manzoni G, Minicozzi A, Coniglio A, Tiberio G, Pacelli F, Rosa F and Nitti D: Validation of the new AJCC TNM staging system for gastric cancer in a large cohort of patients $(n=2,155)$ : focus on the T category. Eur J Surg Oncol 37: 779-785, 2011. PMID: 21726975. DOI: 10.1016/j.ejso.2011.06.001 
3 Hao Y, Yu P, Qian F, Zhao Y, Shi Y, Tang B, Zeng D and Zhang $\mathrm{C}$ : Comparison of laparoscopy-assisted and open radical gastrectomy for advanced cancer: A retrospective study in a single minimally surgery center. Medicine (Baltimore) 95: e3936, 2016. PMID: 27336885. DOI: 10.1097/MD.0000 000000003936

4 Hiki N, Katai H, Mizusawa J, Nakamura K, Nakamori M, Yoshikawa T, Kojima K, Imamoto H, Ninomiya M, Kitano S, Terashima $\mathbf{M}$ and Stomach Cancer Study Group of Japan Clinical Oncology Group: Long-term outcome of laparoscopyassisted distal gastrectomy with suprapancreatic nodal dissection for clinical stage I gastric cancer: a multicenter phase II trial (JCOG0703). Gastric Cancer 21: 155-161, 2018. PMID: 2809 3654. DOI: $10.1007 / \mathrm{s} 10120-016-0687-0$

5 In H, Kantor O, Sharpe SM, Baker MS, Talamonti MS and Posner MC: Adjuvant therapy improves survival for T2N0 gastric cancer patients with sub-optimal lymphadenectomy. Ann Surg Oncol 23: 1956-1962, 2016. PMID: 26753752. DOI: 10.1245/s10434-015-5075-1

6 Bausys R, Bausys A, Vysniauskaite I, Maneikis K, Stratilatovas E and Strupas K: Surgical treatment outcomes of patients with T1-T2 gastric cancer: does the age matter when excellent treatment results are expected? World J Surg Oncol 16: 79, 2018. PMID: 29661204. DOI: 10.1186/s12957-018-1388-4

7 Jucá PC, Lourenço L, Kesley R, Mello EL, Oliveira IM and Correa JH: Comparison of survival and prognostic factors in patients with gastric adenocarcinoma in T2 and T3. Rev Col Bras Cir 39: 377-384, 2012. PMID: 23174788.

8 Huang CM, Wang HM, Zheng CH, Li P, Xie JW, Wang JB, Lin $\mathrm{JX}$ and $\mathrm{Lu} \mathrm{J}$ : Tumor size as a prognostic factor in patients with node-negative gastric cancer invading the muscularis propria and subserosa (pT2-3N0M0 stage). Hepathogastroenterology 60: 799-703, 2013. PMID: 23159390. DOI: 105754/hge12733

9 Park SS, Kim CS, Mok YJ, Kim SJ and Kim HI: Gastric cancer confined to the muscularis propria: A possible candidate for laparoscopic surgery or adjuvant therapy. Scand J Gastroenterol 40: 450-454, 2005. PMID: 16028440.

10 Xu J, Cao H, Yang JY, Suh YS, Kong SH, Kim SH, Kim SG, Lee HJ, Kim WH and Yang HK: Is preoperative staging enough to guide lymph node dissection in clinically early gastric cancer? Gastric Cancer 19: 568-578, 2016. PMID: 26231352. DOI: 10.1007/s10120-015-0512-1

11 Sun Z, Wang ZN, Zhu GL, Huang BJ, Li K, Xu Y, Li DM and $\mathrm{Xu}$ HM: Advanced gastric cancer with early cancer macroscopic appearance: is it worthy of D2 lymphadenectomy? Ann Surg Oncol 17: 1278-1290, 2010. PMID: 20058192. DOI: 10.1245/ s10434-009-0890-x

12 Japanese Gastric Cancer Association: Japanese classification of gastric carcinoma: 3rd English edition. Gastric Cancer 14: 101112, 2011. PMID: 21573743. DOI: 10.1007/s10120-011-0041-5

13 Liu JY, Peng CW, Yang XJ, Huang CQ and Li Y: The prognostic role of AJCC/UICC 8(th) edition staging system in gastric cancer, a retrospective analysis. Am J Transl Res 10: 292-303, 2018. PMID: 29423014.

14 Nakamura K, Tomioku M, Nabeshima K and Nomura E: Clinical implication of the width of subserosal invasion in T3N0 gastric cancer. In Vivo 31: 409-413, 2017. PMID: 28438870. DOI: 10.21873/invivo.11074
15 Son HJ, Myung W, Yoo HS, Park SH, Song SY, Kwon YD and Rhee JC: Prognostic indicators of gastric carcinoma confined to the muscularis propria. Histopathology 51: 105-110, 2007. PMID: 17593085. DOI: 10.1111/j.1365-2559.2007.02725.x

16 Sun Z, Zhu GL, Lu C, Guo PT, Huang BJ, Li K, Xu Y, Wang $\mathrm{ZN}$ and Xu HM: A novel subclassification of pT2 gastric cancers according to the depth of muscularis propria invasion: superficial muscularis propria versus deep muscularis propria/subserosa. Ann Surg 249: 768-775, 2009. PMID: 19387327. DOI: 10.1097/SLA.0b013e3181a3df77

17 Zhang WH, He D, Chen DN, Li TT, Chen XZ, Yang K, Liu K, Zhang B, Chen ZX, Zhou ZG and Hu JK: Comparison between superficial muscularis propria and deep muscularis propria infiltration in gastric cancer patients: A retrospective cohort study. Medicine (Baltimore) 95: e4165, 2016. PMID: 27442638. DOI: 10.1097/MD.0000000000004165

18 Ishigami S, Natsugoe S, Miyazono F, Hata Y, Uenosono Y, Sumikura S, Matsumoto M, Tokuda K, Nakajo A, Hokita S and Aikou T: Clinical merit of subdividing gastric cancer according to invasion of the muscularis propria. Hepatogastroenterology 51: 869-871, 2004. PMID: 15143936.

19 Sanomura Y, Oka S, Tanaka S, Higashiyama M, Yoshida S, Arihiro K, Shimamoto F and Chayama K: Predicting the absence of lymph node metastasis of submucosal invasive gastric cancer: expansion of the criteria for curative endoscopic resection. Scand J Gastroenterol 45: 1480-1487, 2010. PMID: 20645676. DOI: $10.3109 / 00365521.2010 .505659$

20 Kim JY, Kim WG, Jeon TY, Kim GH, Jeong EH, Kim DH, Park DY and Luuwers GY: Lymph node metastasis in early gastric cancer: evaluation of a novel method for measuring submucosal invasion and development of a nodal predicting index. Hum Pathol 44: 2829-2836, 2013. PMID: 24139210. DOI: 10.1016/ j.humpath.2013.07.037

21 Fang WL, Huang KH, Lan YT, Chen MH, Chao Y, Lo SS, Wu CW, Shyr YM and Li AF: The risk factors of lymph node metastasis in early gastric cancer. Pathol Oncol Res 21: 941-946, 2015. PMID: 25749755. DOI: 10.1007/s12253-015-9920-0

22 Choi JY, Park YS, Jung HY, Son DH, Ahn JY, Han S, Lim H, Choi KS, Lee JH, Kim DH, Choi KD, Song HJ, Lee GH and Kim JH: Identifying predictors of lymph node metastasis after endoscopic resection in patients with minute submucosal cancer of the stomach. Surg Endosc 29: 1467-1483, 2015. PMID: 25249150. DOI: $10.1007 / \mathrm{s} 00464-014-3828-8$

23 Soga K, Ichikawa D, Yasukawa S, Kubota T, Kikuchi S, Fujiwara H, Okamoto K, Ochiai T, Sakakura C, Kokuba Y, Yanagisawa A and Otsuji E: Prognostic impact of the width of subserosal invasion in gastric cancer invading the subserosal layer. Surgery 147: 197-203, 2010. PMID: 19758672. DOI: 10.1016/j.surg.2009.06.032

24 Liu X, Long Z, Cai H, Huang H, Shi Y and Wang Y: Analysis of lymph node metastasis correlation with prognosis in patients with T2 gastric cancer. PLoS One 9: e105112, 2014. PMID: 25136920. DOI: 10.1371/journal.pone.0105112

Received May 2, 2019

Revised June 17, 2019

Accepted June 19, 2019 